See Article page 681.

\section{Commentary: The dangers of postoperative acute kidney injury - Vulnerability despite early resolution}

\author{
Glenn J. R. Whitman, MD, and \\ Chirag R. Parikh, MD, PhD
}

In this month's Journal, the article by Cho and colleagues ${ }^{1}$ addresses the issue of immediate postoperative acute kidney injury (AKI), acute kidney disease (AKD) at three months, and chronic kidney disease (CKD) diagnosed at 1 year in patients with valvular heart disease in whom preoperative renal function was normal. Furthermore, the article analyzes outcomes of patients who had complete resolution of their AKI within 3 days of surgery. Of the 1386 patients included in the study, nearly $25 \%$ had development of AKI according to Kidney Disease: Improving Global Outcomes criteria. This is consistent with other publications looking at postoperative AKI in cardiac surgery. ${ }^{2-6}$ The incidence of $\mathrm{AKD}$, defined as elevated creatinine at 3 months, was $15.1 \%$ in patients with AKI versus $4.7 \%$ in those without AKI; similarly, at 1 year, the incidence of CKD was $12.5 \%$ in patients with AKI versus $4.2 \%$ in those without AKI. As the severity of perioperative AKI increased, so did the risks of AKD and CKD. Most impressive was the fact that threefold increases in the incidences of AKD and CKD were seen in the $88 \%$ of patients who had rapid perioperative resolution of AKI.

Among many, we would like to emphasize 2 specific aspects of these results. First, cardiac surgeons need to be cognizant that any perioperative kidney injury, minor to severe, regardless of its resolution, significantly increases postoperative morbidity and mortality. In this study, even among patients in whom AKI had resolved before

\footnotetext{
From the Division of Cardiac Surgery, Department of Surgery and Division of Nephrology, Department of Medicine, Johns Hopkins School of Medicine, Baltimore, Md.

Disclosures: Authors have nothing to disclose with regard to commercial support. Dr Parikh is supported by National Institutes of Health grant RO1HL085757.

Received for publication Oct 22, 2019; revisions received Oct 22, 2019; accepted for publication Oct 22, 2019; available ahead of print Nov 5, 2019.

Address for reprints: Glenn J. R. Whitman, MD, Johns Hopkins Hospital, Zayed Tower, Suite 7107, 1800 Orleans St, Baltimore, MD 21287 (E-mail: gwhitman@ jhmi.edu).

J Thorac Cardiovasc Surg 2021;161:689-90

$0022-5223 / \$ 36.00$

Copyright (C) 2019 by The American Association for Thoracic Surgery

https://doi.org/10.1016/j.jtcvs.2019.10.107
}

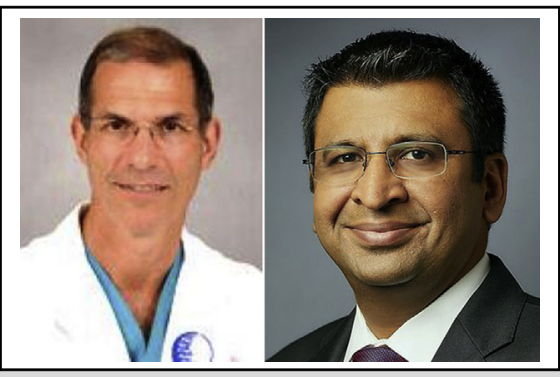

Glenn J. R. Whitman, MD (left), and Chirag R. Parikh, $\mathrm{MD}, \mathrm{PhD}$ (right)

\author{
CENTRAL MESSAGE \\ Even with resolution, post-car- \\ diac surgery acute kidney injury \\ leaves patients vulnerable to sig- \\ nificant renal and cardiovascular \\ morbidity. It is our responsibility \\ to prevent or minimize this harm.
}

discharge, the risk of requiring dialysis at 3 months was $5.7 \%$, versus $0.2 \%$ among those without $\mathrm{AKI}$, and the risk of death was 3.6 versus $0.7 \%$. In those with AKI without recovery, these risks were close to an order of magnitude higher (see Figure 1). That these events should befall patients with preoperative normal renal function is regrettable, for certain, and the burden of minimizing these long-term sequelae falls on our shoulders.

Parikh and colleagues ${ }^{7}$ have described several biomarkers of injury and inflammation that are elevated after cardiac surgery and are associated with adverse cardiovascular and kidney outcomes. Even without a creatinine elevation, a complex interplay of adaptive and maladaptive biologic processes in these patients determines the development of AKD and CKD. ${ }^{8}$ Close follow-up of these patients after discharge must occur to assist with optimizing blood pressure, minimizing heart failure by optimal volume and hemodynamic control, and prescribing appropriate medicines, such as renin-angiotensin-aldosterone system agents and sodium-glucose cotransporter- 2 inhibitors, which have demonstrated renal and cardiovascular protection in clinical trials. ${ }^{9}$

Second, given that patients with normal preoperative renal function had early AKI occur, intraoperative injury must be playing a role. Recent evidence ${ }^{10,11}$ has implicated a threshold oxygen delivery during cardiopulmonary bypass of roughly $250 \mathrm{~mL} \mathrm{O} \mathrm{O}_{2} / \mathrm{min} / \mathrm{m}^{2}$ (eg, maintaining a cardiac index $>2.4$ with a hemoglobin $80 \mathrm{mg} / \mathrm{mL}$ ) as instrumental 


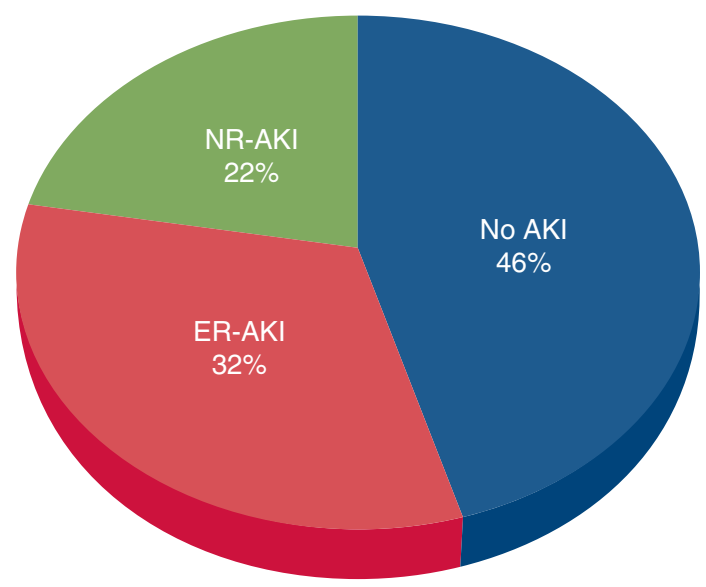

FIGURE 1. Distributions of the 3 types of postoperative renal function among the 99 patients who at 12 months had died or had chronic kidney disease develop. $N R$, No recovery; $A K I$, acute kidney injury; $E R$, early recovery.

in preventing clinical and subclinical AKI. Indeed, by addressing this as well as several other issues unique to cardiopulmonary bypass, Magruder and associates ${ }^{12}$ decreased postoperative AKI by more than $50 \%$.

We congratulate Cho and colleagues ${ }^{1}$ for identifying the long-term sequelae of "clinically resolved AKI" at discharge. Further advances might be facilitated by perioperative scoring systems, identifying patients who would benefit from postdischarge follow-up to prevent CKD.

\section{References}

1. Cho JS, Shim JK, Lee S, Song JW, Choi N, Lee S, et al. Chronic progression of cardiac surgery associated acute kidney injury: intermediary role of acute kidney disease. J Thorac Cardiovasc Surg. 2021;161:681-8.e3.

2. Koyner JL, Garg AX, Coca SG, Sint K, Thiessen-Philbrook H, Patel UD, et al; TRIBE-AKI Consortium. Biomarkers predict progression of acute kidney injury after cardiac surgery. J Am Soc Nephrol. 2012;23: 905-14.

3. Xu JR, Zhu JM, Jiang J, Ding XQ, Fang Y, Shen B, et al. Risk factors for long-term mortality and progressive chronic kidney disease associated with acute kidney injury after cardiac surgery. Medicine (Baltimore). 2015;94: e2025.

4. Lafrance JP, Miller DR. Acute kidney injury associates with increased long-term mortality. J Am Soc Nephrol. 2010;21:345-52.

5. Crawford TC, Magruder JT, Grimm JC, Lee SR, Suarez-Pierre A, Lehenbauer D, et al. Renal failure after cardiac operations: not all acute kidney injury is the same. Ann Thorac Surg. 2017;104:760-6.

6. Thakar CV, Worley S, Arrigain S, Yared JP, Paganini EP. Influence of renal dysfunction on mortality after cardiac surgery: modifying effect of preoperative renal function. Kidney Int. 2005;67:1112-9.

7. Parikh CR, Devarajan P, Zappitelli M, Sint K, Thiessen-Philbrook H, Li S, et al; TRIBE-AKI Consortium. Postoperative biomarkers predict acute kidney injury and poor outcomes after pediatric cardiac surgery. J Am Soc Nephrol. 2011;22: 1737-47.

8. Basile DP, Bonventre JV, Mehta R, Nangaku M, Unwin R, Rosner MH, et al; ADQI XIII Work Group. Progression after AKI: understanding maladaptive repair processes to predict and identify therapeutic treatments. J Am Soc Nephrol. 2016;27:687-97.

9. Chawla LS, Bellomo R, Bihorac A, Goldstein SL, Siew ED, Bagshaw SM, et al; Acute Disease Quality Initiative Workgroup 16. Acute kidney disease and renal recovery: consensus report of the Acute Disease Quality Initiative (ADQI) 16 Workgroup. Nat Rev Nephrol. 2017;13:241-57.

10. Ranucci M, Romitti F, Isgrò G, Cotza M, Brozzi S, Boncilli A, et al. Oxygen delivery during cardiopulmonary bypass and acute renal failure after coronary operations. Ann Thorac Surg. 2005;80:2213-20.

11. Magruder JT, Dungan SP, Grimm JC, Harness HL, Wierschke C, Castillejo S, et al. Nadir oxygen delivery on bypass and hypotension increase acute kidney injury risk after cardiac operations. Ann Thorac Surg. 2015; 100:1697-703.

12. Magruder JT, Crawford TC, Harness HL, Grimm JC, Suarez-Pierre A, Wierschke C, et al. A pilot goal-directed perfusion initiative is associated with less acute kidney injury after cardiac surgery. J Thorac Cardiovasc Surg. 2017; 153:118-25.e1. 